\title{
Prediabetes and Undiagnosed Diabetes Mellitus: The Hidden Danger
}

\author{
${ }^{1}$ Suprava Patel, ${ }^{2}$ Rachita Nanda, ${ }^{3}$ Jessy Abraham, ${ }^{4}$ Sibasish Sahoo, ${ }^{5}$ Anirban Ganguly, ${ }^{6}$ Eli Mohapatra
}

\begin{abstract}
Introduction: Diabetes is considered as a major challenge to the public health system in India. Recent articles clearly mention that the hidden danger in the form of prediabetes and undiagnosed diabetes is greatly adding to the burden silently. Awareness regarding the same, particularly among youth, can help diagnose the condition very early and thus, initiate early management.
\end{abstract}

Objectives: With an aim to estimate the frequency of prediabetes and undiagnosed diabetes in the adult population, a camp was organized in our institute to screen the adults in our locality by estimating fasting plasma glucose (FPG) and glycosylated hemoglobin (HbA1c).

Materials and methods: A total of 246 individuals were selected for analysis after excluding the known diabetic cases. Height, weight, pulse, blood pressure (BP), waist circumference, and body mass index (BMI) were measured. Plasma fasting sugar and fasting serum lipid profile were analyzed. The $\mathrm{HbA} 1 \mathrm{c}$ was estimated in hyperglycemic subjects.

Results: The frequency of hyperglycemia in the study population was found to be $28 \%$. The total frequency of prediabetes was $18.3 \%$ and that of undiagnosed diabetes was $9.75 \%$. The raised sugar could be significantly associated with age, waist circumference, BMI, hypertriglyceridemia, and cholesterol-tohigh-density lipoprotein (Chol:HDL) ratio. Aging, greater BMI, hypertriglyceridemia, and raised low-density lipoprotein (LDL) depicted significant odds ratio $(\mathrm{OR})$ to predict the risk factor for diabetes.

Conclusion: The hidden burden of diabetes in our locality is quite high, which, if not taken care, would result in a public health catastrophe.

Keywords: Diabetes, Dyslipidemia, Fasting plasma glucose, Glycosylated hemoglobin, Prediabetes.

How to cite this article: Patel S, Nanda R, Abraham J, Sahoo S, Ganguly A, Mohapatra E. Prediabetes and Undiagnosed Diabetes Mellitus: The Hidden Danger. Indian J Med Biochem 2017;21(2):91-95.

\section{Source of support: Nil}

Conflict of interest: None

\footnotetext{
${ }^{1,3}$ Associate Professor, ${ }^{2}$ Additional Professor, ${ }^{4,5}$ Senior Resident ${ }^{6}$ Professor

${ }^{1-6}$ Department of Biochemistry, All India Institute of Medical Sciences, Raipur, Chhattisgarh, India
}

Corresponding Author: Suprava Patel, Associate Professor Department of Biochemistry, All India Institute of Medical Sciences, Raipur, Chhattisgarh, India, Phone: +918518881707 e-mail:dr_suprava@yahoo.co.in

\section{INTRODUCTION}

India is currently facing a major challenge of an epidemic burden of diabetes mellitus (DM), presently populated with 69.2 million diabetic individuals. ${ }^{1}$ India is among the top three countries with high diabetic population, and the burden of undiagnosed DM in India is at about $52 \%$ (36 million adults). India is the prime focus area for diabetes-related research because of three reasons: (i) It is the second largest country of adult diabetic individuals, after China; (ii) it is regarded as the second largest nation to be populated with children with type 1 diabetes $(70,200)$, after USA; and (iii) it is the largest contributor to regional mortality attributable to diabetes (one million deaths). ${ }^{2}$ Unlike diabetes, prediabetes and undiagnosed diabetes are the hidden dangers that would further accelerate the diabetes burden in future and worsen the scenario. Estimating their prevalence would be a vital index to calculate the actual burden of the disorder and thus, enable to formulate and implement appropriate policies before it turns to be a public health catastrophe.

In type II DM, relative deficiency of insulin accelerates the rate of lipolysis in insulin-dependent tissues as in adipose tissues and muscles resulting in mobilization of free fatty acids to liver where it acts as precursor for triglyceride (TG) synthesis. Hence, dyslipidemia has been suggested by many authors as a notable risk factor for insulin resistance (IR) and DM. ${ }^{2-4}$

\section{OBJECTIVES}

With an aim to screen for undiagnosed DM and prediabetic profile in the adult population of Raipur city and estimate the frequency of DM and prediabetic cases in the community, our department arranged a camp in the institute.

\section{MATERIALS AND METHODS}

A camp was organized by our department in the campus of the institute. Concise instructions and preparatory information (overnight fasting of 8 hours) inscribed in pamphlets, in local language and English, were distributed in the city. This camp was approved by our Institutional Board.

A total of 298 individuals got enrolled for the camp. All individuals were asked to sign the informed consent 
form followed by registration. Height, weight, and waist circumference were measured, and BMI was calculated for all of them. Pulse and BP were measured by manual sphygmomanometer in sitting position.

Fasting plasma glucose and serum lipid profile (cholesterol, TG, HDL) were estimated immediately after in automated analyzer (Biosystems B400) and $\mathrm{HbA1c}$ in D10 hematoanalyzer. The LDL was calculated by Friedewald's method. Individuals with FPG > $100 \mathrm{mg} / \mathrm{dL}$ were subjected to estimation of $\mathrm{HbA} 1 \mathrm{c}$ to assess their metabolic state and categorize them as diabetic and prediabetic.

Forty-six known diabetic cases also got enrolled, which were excluded during the analysis in order to have the actual burden of undiagnosed cases. Six individuals with known sickle cell disease had raised FPG and elevated $\mathrm{HbA1c}$ levels and were also excluded during analysis.

Individuals were categorized as normoglycemic (FPG $\leq 100 \mathrm{mg} / \mathrm{dL}$ ) and hyperglycemic (FPG > $100 \mathrm{mg} / \mathrm{dL}$ ).

All hyperglycemics were subcategorized as prediabetic and diabetic as per the diagnostic criteria laid by the American Diabetes Association. ${ }^{5}$

\section{Diabetics}

Individuals with FPG $\geq 126 \mathrm{mg} / \mathrm{dL}$ and $/$ or $\mathrm{HbA1c} \geq 6.5 \%$. If any patient has $\mathrm{A} 1 \mathrm{c} \geq 6.5 \%$, but FPG $<126 \mathrm{mg} / \mathrm{dL}$, that person was considered as diabetic.

\section{Prediabetics}

Individuals with FPG between 101 and $125 \mathrm{mg} / \mathrm{dL}$ and / or $\mathrm{HbA} 1 \mathrm{c} 5.7$ and $6.4 \%$.

Estimation of $\mathrm{HbA1c}$ was by the ion exchange highperformance liquid chromatography method as certified by the National Glycohemoglobin Standardization Program, which is supposed to be advantageous over FPG and oral glucose tolerance testing because of its greater preanalytical stability and minimum interference by day-to-day activity and stress. ${ }^{5,6}$

Desirable ranges for the variables measured were as per Atherosclerotic Cardiovascular Disease Risk Categories given in Table $1 .^{7}$

Statistical analysis was performed using IBM Statistical Package for the Social Sciences version 16.0. Causal relationship between the variables was determined by chi-square $\left(\chi^{2}\right)$ test. The OR with $95 \%$ confidence interval (CI) was estimated using logistic regression predicting the factors associated with diabetes. For two-tailed p-values of $<0.05$ were considered significant, with $95 \%$ CIs.

\section{RESULTS}

The data analysis revealed that $67 \%(n=165)$ of the participants were young adults of age group less than
Table 1: Desirable range for the measured variables

\begin{tabular}{ll}
\hline Variables & Desirable range/0 risk factor \\
\hline Waist circumference & Men: $<94 \mathrm{~cm}$; Women: $<80 \mathrm{~cm}$ \\
BMI & $18.5-24.9 \mathrm{~kg} / \mathrm{m}^{2}$ \\
Pulse & $60-100 \mathrm{per} \mathrm{min}$ \\
BP & $<140 / 90 \mathrm{~mm} \mathrm{Hg}$ \\
FPG & $<126 \mathrm{mg} / \mathrm{dL}$ \\
HbA1c & $<5.7 \%$ \\
Serum cholesterol & $<200 \mathrm{mg} / \mathrm{dL}$ \\
Serum TG & $<150 \mathrm{mg} / \mathrm{dL}$ \\
Serum HDL & $\geq 60 \mathrm{mg} / \mathrm{dL}$ \\
Serum VLDL & $\leq 30 \mathrm{mg} / \mathrm{dL}$ \\
Serum LDL & $<130 \mathrm{mg} / \mathrm{dL}$ \\
Chol:HDL & $3.3-4.4$ \\
LDL:HDL & $0.5-3.0$ \\
\hline VLDL: Very low-densty &
\end{tabular}

VLDL: Very low-density lipoprotein

Table 2: Distribution of study population according to fasting blood sugar level

\begin{tabular}{lll}
\hline Dependant variables & Frequency & Percentage \\
\hline Normoglycemic $(\leq 100 \mathrm{mg} / \mathrm{dL})$ & $177(\mathrm{n}=246)$ & 71.95 \\
Prediabetic $(>100 \mathrm{and}<126 \mathrm{mg} / \mathrm{dL})$ & $45(\mathrm{n}=246)$ & 18.30 \\
Diabetic $(\geq 126 \mathrm{mg} / \mathrm{dL})$ & $24(\mathrm{n}=246)$ & 9.75 \\
Raised HbA1c $(\geq 5.7 \%)$ & $33(\mathrm{n}=69)$ & 47.9 \\
\hline
\end{tabular}

45 years. The frequency of hyperglycemia was calculated to be $28 \%(69 / 246)$ in this community (Table 2$)$. The incidence of prediabetes and diabetes was observed to be respectively, $18.3(n=45)$ and $9.7 \%(n=24)$. About $47.9 \%(n=33)$ of hyperglycemic subjects depicted raised $\mathrm{HbA1c}$ levels.

The mean age of participants was $38.7 \pm 10.2$ years, frequency of hypertension was $38.6 \%, 54.9 \%$ had greater waist circumference, and $62.2 \%$ recorded high BMI, of which $25 \%(n=38 / 153)$ were obese. Some sort of addiction history like smoking, tobacco chewing, regular alcohol intake, and other chewing habits was found in $26 \%$ people, family history was positive in $28 \%$ cases, $49.2 \%$ gave history for exercising regularly, and $72 \%$ of all study subjects were found to be vegetarians. Dyslipidemia was represented in $47.5 \%$ of the study population.

The $\chi^{2}$ test in Table 3 revealed that age group, waist circumference, and BMI have a significant $(\mathrm{p}<0.05)$ difference in proportion within each group. Participants of age group $\geq 45$ years have 2.68 times more risk of diabetes as compared with those participants within the age group 18 to 44 years (CI 1.5-4.78; $\mathrm{p}<0.01$ ).

As compared with subjects with normal BMI, those who are underweight tend to have low rate of diabetes (OR: 0$)$; whereas obese $\left(\geq 30 \mathrm{~kg} / \mathrm{m}^{2}\right)$ people are more prone to be diagnosed as diabetes (OR: 3.69; $\mathrm{p}<0.01$ ).

As shown in Table 4, associated hypertriglyceridemia $(\mathrm{TG} \geq 150 \mathrm{mg} / \mathrm{dL})$ raises the risk $2.21(\mathrm{p}<0.05)$ times for diabetes against the desirable level of TG. Individuals 
Table 3: Percentage distribution of diabetes status by physiological characteristics by chi-squared test

\begin{tabular}{|c|c|c|c|c|c|}
\hline Variables & Normoglycemic & Prediabetic & Diabetic & Total & $p$-value \\
\hline \multicolumn{6}{|l|}{ Age group (years) } \\
\hline $18-24$ & 15 & 0 & 0 & 15 & \multirow[t]{4}{*}{$0.006^{*}$} \\
\hline $25-34$ & 79 & 14 & 5 & 98 & \\
\hline $35-44$ & 36 & 10 & 6 & 52 & \\
\hline$\geq 45$ & 47 & 21 & 13 & 81 & \\
\hline \multicolumn{6}{|l|}{ Gender } \\
\hline Male & 124 & 31 & 18 & 173 & \multirow[t]{2}{*}{0.86} \\
\hline Female & 53 & 14 & 6 & 73 & \\
\hline \multicolumn{6}{|l|}{ Blood pressure $(\mathrm{mm} \mathrm{Hg})$} \\
\hline Normotensive & 114 & 24 & 13 & 151 & \multirow[t]{2}{*}{0.295} \\
\hline Hypertensive & 63 & 21 & 11 & 95 & \\
\hline \multicolumn{6}{|c|}{ Waist circumference $(\mathrm{cm})$} \\
\hline Normal & 86 & 12 & 13 & 111 & \multirow[t]{2}{*}{$0.02^{*}$} \\
\hline High & 91 & 33 & 11 & 135 & \\
\hline \multicolumn{6}{|l|}{$B M I\left(k g / m^{2}\right)$} \\
\hline Normal (18.5-24.9) & 74 & 7 & 9 & 90 & \multirow[t]{4}{*}{$0.007^{*}$} \\
\hline Underweight $(<18.5)$ & 3 & 0 & 0 & 3 & \\
\hline Overweight (25-29.9) & 8 & 24 & 11 & 115 & \\
\hline Obese $(\geq 30)$ & 20 & 14 & 4 & 38 & \\
\hline \multicolumn{6}{|l|}{ Addiction } \\
\hline Yes & 43 & 14 & 7 & 64 & \multirow[t]{2}{*}{0.605} \\
\hline No & 134 & 31 & 17 & 182 & \\
\hline \multicolumn{6}{|l|}{ Family history } \\
\hline Yes & 41 & 8 & 5 & 54 & \multirow[t]{2}{*}{0.731} \\
\hline No & 136 & 37 & 19 & 192 & \\
\hline \multicolumn{6}{|l|}{ Diet } \\
\hline Vegetarian & 124 & 35 & 19 & 178 & \multirow[t]{2}{*}{0.43} \\
\hline Mixed & 53 & 10 & 5 & 68 & \\
\hline \multicolumn{6}{|l|}{ Exercise (regular) } \\
\hline Yes & 85 & 24 & 12 & 121 & \multirow[t]{2}{*}{0.81} \\
\hline No & 92 & 21 & 12 & 125 & \\
\hline
\end{tabular}

Table 4: Lipid profile association with diabetes

\begin{tabular}{|c|c|c|c|c|}
\hline \multirow[b]{2}{*}{ Variables } & \multirow[b]{2}{*}{ Odds ratio } & \multicolumn{2}{|c|}{$95 \% \mathrm{Cl}$} & \multirow[b]{2}{*}{$p$-value } \\
\hline & & Lower & Upper & \\
\hline \multicolumn{5}{|l|}{ Total cholesterol (mg/dL) } \\
\hline \multicolumn{5}{|l|}{ Desirable $(<200)$} \\
\hline Moderate and high risk $(\geq 200)$ & 0.99 & 0.49 & 2.01 & 0.99 \\
\hline \multicolumn{5}{|l|}{$T G(m g / d L)$} \\
\hline \multicolumn{5}{|l|}{ Desirable $(<150)$} \\
\hline Moderate and high risk $(\geq 150)$ & 2.21 & 1.20 & 4.09 & $0.011^{*}$ \\
\hline \multicolumn{5}{|l|}{$H D L(m g / d L)$} \\
\hline \multicolumn{5}{|l|}{ Desirable $(\geq 60)$} \\
\hline Moderate and high risk $(<60)$ & 1.20 & 0.30 & 4.69 & 0.79 \\
\hline \multicolumn{5}{|l|}{$L D L(m g / d L)$} \\
\hline \multicolumn{5}{|l|}{ Desirable $(<129)$} \\
\hline Moderate and high risk ( $\geq 129)$ & 2.1 & 1.12 & 3.93 & $0.04^{*}$ \\
\hline \multicolumn{5}{|l|}{ Chol:HDL } \\
\hline Desirable (3.3-4.4) & 1.726 & 0.822 & 3.623 & 0.14 \\
\hline \multicolumn{5}{|l|}{ Moderate and high risk (> 4.4) } \\
\hline \multicolumn{5}{|l|}{$L D L: H D L$} \\
\hline \multicolumn{5}{|l|}{ Desirable (0.5-3.0) } \\
\hline Moderate and high risk $(>3.0)$ & 1.18 & 0.65 & 2.16 & 0.57 \\
\hline
\end{tabular}


Table 5: Pearson correlation between fasting plasma sugar and physiological and biochemical variables

\begin{tabular}{llcl}
\hline Blood sugar & $\begin{array}{l}\text { Pearson } \\
\text { correlation }\end{array}$ & $\begin{array}{l}\text { Significant } \\
\text { (two-tailed) }\end{array}$ & $n$ \\
\hline Age & 0.215 & $<0.001^{* *}$ & 246 \\
Pulse & 0.112 & 0.080 & 246 \\
BP & 0.112 & $0.008^{*}$ & 246 \\
Waist circumference & 0.117 & 0.067 & 246 \\
BMI & 0.135 & $0.035^{*}$ & 246 \\
Blood sugar & 1 & & 246 \\
TChol & 0.168 & $0.008^{*}$ & 246 \\
TG & 0.320 & $<0.001^{* *}$ & 246 \\
HDL & -0.036 & 0.576 & 246 \\
LDL & 0.100 & 0.117 & 246 \\
VLDL & 0.321 & $<0.001^{* *}$ & 246 \\
TChol:HDL & 0.184 & $0.004^{*}$ & 246 \\
LDL:HDL & 0.127 & $0.047^{*}$ & 246 \\
\hline
\end{tabular}

${ }^{*} p<0.05$ significant difference

with elevated LDL $(\geq 129 \mathrm{mg} / \mathrm{dL})$ are at a 2.1 times more risk for diabetes in comparison with those with normal levels $(\mathrm{p}<0.05)$.

Pearson correlation analysis demonstrated significant positive correlation between FPG and age $(\mathrm{p}<0.01)$, BMI $(p<0.05)$ TC $(p<0.001)$, very low-density lipoprotein (VLDL; $\mathrm{p}<0.001)$, Chol:HDL ( $<<0.01)$, and HDL:LDL $(\mathrm{p}<0.05)$ as tabulated in Table 5.

\section{DISCUSSION}

The result of one-time analysis of the adult participants who attended the camp for screening tests for diabetes and who otherwise had never been diagnosed as diabetic or prediabetic revealed an incidence of prediabetes and undiagnosed diabetes, together, to be $28 \%$. Further analysis of $\mathrm{HbA} 1 \mathrm{c}$ in these subjects confirmed diabetes in $9.7 \%$, whereas $18.3 \%$ individuals were in prediabetic group. The prevalence of newly detected diabetes in Indian Council of Medical Research-India Diabetes (ICMR-INDIAB) study population $(n=13,055)$ was reported to be $4.4 \%$ in Tamil Nadu (5.2\% urban and 3.8\% rural), 5.9\% in Maharashtra (7.2\% urban and $4.9 \%$ rural), $2.9 \%$ in Jharkhand (5.1\% urban and $2.3 \%$ rural), and $7.4 \%$ in Chandigarh (7.6\% urban and $5.2 \%$ rural). The prevalence of prediabetes in the same study was respectively, 8.3, 12.8, 8.1, and $14.6 \% .{ }^{8}$ Small-scale studies are being carried in different states of India. Of all the published data, highest prevalence of diabetes reported until date is from Ernakulum, Kerala (19.5\%) and lowest from Kashmir valley (6.1\%). ${ }^{9}$ Provided the patients complied with proper fasting condition prior to analysis and the history provided were true and there was no misleading, our data conformed with the prevalence data being depicted by the ICMR study and other studies. As per the above data documented, the frequency of prediabetes (18.3\%) in this area of the state is estimated to be the highest of all.

As per the Chhattisgarh annual health survey 2011to 12 fact sheet, total population of diagnosed diabetic cases in the state was 1,484 per 100,000 population $(1.4 \%)$ and that in Raipur city was reported to be 1,960 per 100,000 population $(1.9 \%) .{ }^{10}$ However, prediabetes and undiagnosed diabetes data were not available in the fact sheet. The difference in frequency percentage could be attributed to the fact that we did not call for a second time test for confirmation or there might have been differences in the performance methodology, the reference values being compared, availability of quality control laboratories, or due to differences in the guidelines being followed.

Studies have been published depicting poor glycemic control among subjects with newly diagnosed diabetes in India. ${ }^{11}$ Ramachandran et $\mathrm{al}^{12}$ recorded poor glycemic control in $71.2 \%$ subjects. Only about $31 \%$ subjects had $\mathrm{HbA} 1 \mathrm{c}$ below $7.0 \%$, whereas 19 to $20 \%$ persons either did not evaluate or were not aware of the test. Our participants documented raised $\mathrm{HbA1c}(\geq 5.7 \%)$ level in $47.9 \%$ of all hyperglycemics. Of the 24 diabetic cases, $37.5 \%$ $(n=9)$ reflected poor glycemic control (HbA1c $\geq 7.0)$.

The major participants in this camp were found to be young individuals ( $\leq 40$ years) who represented $58 \%$ of the whole study population. This reflects the magnitude of awareness among the youth toward their health.

The rising trend of FPG and $\mathrm{HbA} 1 \mathrm{c}$ correlated significantly with age and reflected the impact of aging on IR. The result corroborated with various studies that explain the role of systemic inflammatory response during the aging process. In accordance to previously published articles, our analysis showed association of diabetes and prediabetic state with greater abdominal obesity and BMI. However, it showed significant positive correlation with BMI, which was found to be an independent risk factor for DM. Indian's body fat content is comparatively higher as compared with their peer groups in the Western countries. As per WHO expert consultation, appropriate BMI should be revised and standardized based on the regional population anthropometric measurements. 13,14

The FPG correlated positively with serum cholesterol, TG, Chol:HDL, and LDL:HDL ratios, but dyslipidemia in the form of hypertriglyceridemia and raised LDL level only were indicated to be significant risk factors for diabetes and prediabetes. Park et $\mathrm{al}_{1}{ }^{3}$ in their study, had proposed that the best marker for IR was TG. Dyslipidemia observed in our study group was limited to hypertriglyceridemia and raised LDL level only. No causal association could be analyzed for FPG and $\mathrm{HbA1c}$ with other metabolic profiles like total serum cholesterol, serum HDL, Chol:HDL, and LDL:HDL. This could be 
explained by the fact that significantly higher number of individuals were in the prediabetic group, who might not have developed dyslipidemia and metabolic derangements to be significantly associated with FPG and HbA1c. Early diagnosis and management would improve not only the health status of the individual, but also the health index of the area by reducing the incidence and financial burden of comorbidities and complications arising due to IR and metabolic aberrations.

Some of the limitations in this analysis were: (i) Postprandial plasma glucose was not evaluated; (ii) second sample on different occasion for confirmation of FPG level could not be determined; (iii) other associated endocrine disorders like thyroid, adrenal, and pituitary hormone imbalances that could affect the glucose homeostasis were not estimated.

\section{CONCLUSION}

The burden revealed in this study will be an eye opener for the health system to initiate and implement awareness programs and strategize health care policies to combat the catastrophic burden of this epidemic. Early diagnosis no doubt would reduce the disease burden in the future and, thus, upgrade our health index by lowering the chronicity of the disease. More strategically planned health camps and large-scale multicentric studies involving all age groups from different geographical locations and racial and ethnical distributions would aid in a providing more accurate data of the disease burden.

\section{ACKNOWLEDGMENT}

Authors would like to thank all the technical and nontechnical staff of the department for organizing the camp. They are very grateful to the Admin and Finance sections of the institute for providing financial support. The authors are also thankful to Dr Kittu Bardia, MDS (Public Health Dentistry), for her assistance in statistical analysis of the data.

\section{REFERENCES}

1. Patnaik PK, Jain KK, Chandra P, Pathak J, Raman KV, Shah A. Diabetes in India: Measuring the dynamics of a public health catastrophe. J Soc Health Diabetes 2016 Aug;4(2):77-84.

2. Kim H, Lee M, Kim H, Lee K, Chang S, Kim V, Myong JP, Jeon S. Factors affecting diabetic screening behavior of Korean adults: a multilevel analysis. Asian Nurs Res (Korean Soc Nurs Sci) 2013 Jun;7(2):67-73.
3. Park SY, Cho YJ, Lee SR, Chung H, Jeong K. Triglyceride is a useful surrogate marker for insulin resistance in Korean women with polycystic ovary syndrome. Yonsei Med J 2015 May;56(3):785-792.

4. Kannel WB, Vasan RS, Keyes MJ, Sullivan LM, Robins SJ. Usefulness of the triglyceride: high density lipoprotein versus the cholesterol: high density lipoprotein ratio for predicting insulin resistance and cardiometabolic risk (from the Framingham Offspring Cohort). Am J Cardiol 2008 Feb;101(4):497-501.

5. American Diabetes Association. ADA: standards of medical care in diabetes - 2017. J Clin Appl Res Educ 2017 Jan;40(Suppl 1): S1-S142.

6. NGSP, Harmonizing Hemoglobin A1c Testing. List of NGSP certified methods (updated 2/17, listed by date certified). 2017. [cited 2017 Feb 5]. Available from: http://www.ngsp. org/docs/methods.pdf.

7. Jellinger PS, Smith DA, Mehta AE, Ganda O, Handelsman Y, Rodbard HW, Shepherd MD, Seibel JA, AACE Task Force for Management of Dyslipidemia and Prevention of Atherosclerosis. American Association of Clinical Endocrinologists' Guidelines for Management of Dyslipidemia and Prevention of Atherosclerosis: executive summary. Endocr 2012 MarApr;18(2):269-293.

8. Anjana RM, Pradeepa R, Deepa M, Datta M, Sudha V, Unnikrishnan R, Bhansali A, Joshi SR, Joshi PP, Yajnik CS, et al. Prevalence of diabetes and prediabetes (impaired fasting glucose and/or impaired glucose tolerance) in urban and rural India: phase I results of the Indian Council of Medical Research-INdia DIABetes (ICMR-INDIAB) study. Diabetologia 2011 Dec;54(12):3022-3027.

9. Tandon, N.; Raizada, N. The burden of diabetes in India (revision number 8). In: Diapedia. Amsterdam: Diapedia. org; 2014. [cited 2017 Feb 4]. Available from: http://www. diapedia.org/1105045828/rev/8.

10. Annual Health Survey 2011-12. Chhattisgarh. New Delhi: Office of Registrar general and census Commissioner, India. [cited 2017 Feb 4]. Available from: http://www. censusindia.gov.in/vital_statistics / AHSBulletins / AHS_ Factsheets_2011_12/Chhattisgarh_Factsheet_2011-12.pdf.

11. Unnikrishnan R, Anjana RM, Deepa M, Pradeepa R, Joshi SR, Bhansali A, Dhandania VK, Joshi PP, Madhu SV, Rao PV, et al. Glycemic control among individuals with self-reported diabetes in India--the ICMR-INDIAB Study. Diabetes Technol Ther 2014 Sep;16(9):596-603.

12. Ramachandran A, Mary S, Sathish CK, Selvam S, Catherin Seeli A, Muruganandam M, Yamuna A, Murugesan N, Snehalatha $\mathrm{Cl}$. Population based study of quality of diabetes care in southern India. J Assoc Physicians India 2008 Jul;56:513-516.

13. Shiwaku K, Anuurad E, Enkhmaa B, Kitajima K, Yamane Y. Appropriate BMI for Asian populations. Lancet 2004 Mar; 363(9414):1077.

14. WHO Expert Consultation. Appropriate body-mass index for Asian populations and its implications for policy and intervention strategies. Lancet Lond Engl 2004 Jan;363(9403): 157-163. 